This document is confidential and is proprietary to the American Chemical Society and its authors. Do not copy or disclose without written permission. If you have received this item in error, notify the sender and delete all copies.

\title{
Coexistence of Helical Morphologies in Columnar Stacks of Star-Shaped Discotic Hydrazones
}

\begin{tabular}{|r|l|}
\hline Journal: & Journal of the American Chemical Society \\
\hline Manuscript ID: & ja-2013-029186.R2 \\
\hline Manuscript Type: & Article \\
\hline Complete List of Authors: & $\begin{array}{l}\text { Shu, Jie; Max Planck Institute for Polymer Research, } \\
\text { Dudenko, Dmytro; Max Planck Institute for Polymer Research, } \\
\text { Esmaeili, Morteza; Norwegian University of Science and Technology, } \\
\text { Department of Physics } \\
\text { Park, Jun Ha; Seoul National University, Materials Science and Engineering } \\
\text { Puniredd, Sreenivasa; Max Planck Institute for Polymer Research, } \\
\text { Chang, Ji Young; Seoul National University, Materials Science and } \\
\text { Engineering } \\
\text { Breiby, Dag; Norwegian University of Science and Technology, Department } \\
\text { of Physics } \\
\text { Pisula, Wojciech; Max Planck Institute for Polymer Research, } \\
\text { Hansen, Michael Ryan; Max Planck Institute for Polymer Research, Polymer } \\
\text { Spectroscopy }\end{array}$ \\
\hline
\end{tabular}

\section{SCHOLARONE ${ }^{\text {m }}$}

Manuscripts 
Coexistence of Helical Morphologies in Columnar Stacks of Star-Shaped Discotic Hydrazones

Jie Shu, ${ }^{1}$ Dmytro Dudenko, ${ }^{1}$ Morteza Esmaeili, ${ }^{3}$ Jun Ha Park, ${ }^{2}$ Sreenivasa Reddy Puniredd, ${ }^{1}$ Ji Young Chang, ${ }^{2}$ Dag Werner Breiby, ${ }^{3}$ Wojciech Pisula, ${ }^{1, *}$ and Michael Ryan Hansen ${ }^{1, *}$

${ }^{1}$ Max Planck Institute for Polymer Research, Ackermannweg 10, 55128 Mainz, Germany

${ }^{2}$ Department of Materials Science and Engineering, College of Engineering, Seoul National University, Seoul 151-744, Korea

${ }^{3}$ Department of Physics, Norwegian University of Science and Technology, Høgskoleringen 5, 7491 Trondheim, Norway

$\$$ Present address: Evonik Industries AG, Kirschenallee, 64293 Darmstadt, Germany

RECEIVED DATE (to be automatically inserted after your manuscript is accepted if required according to the journal that you are submitting your paper to)

Corresponding authors: pisula@mpip-mainz.mpg.de, mrh@mpip-mainz.mpg.de

\begin{abstract}
Discotic hydrazone molecules are of particular interest as they form discotic phases where the discs are rigidified by intramolecular hydrogen bonds. Here, we investigate the thermotropic behavior and solid-state organizations of three discotic hydrazone derivatives with dendritic groups attached to their outer peripheries, containing six, eight and ten carbons of linear alkoxy chains. Based on two-dimensional Wide Angle X-ray Scattering (2DWAXS), the elevated temperature liquid crystalline (LC) phases were assigned to a hexagonal columnar ( $\mathrm{Col}_{\mathrm{h}}$ ) organization with non-tilted hydrazone discs for all three compounds. Using WAXS, advanced solid-state nuclear magnetic resonance (SSNMR) techniques, and $a b$ initio computations, the compounds with six and ten carbons of achiral alkoxy side chains were further subjected to studies at $25^{\circ} \mathrm{C}$, revealing complex crystalline phases with rigid columns and flexible side chains. This combined approach led to models of coexisting helical columnar stacking morphologies for both systems with two different tilt/pitch angles between successive hydrazone molecules. The
\end{abstract}


differences in tilt/pitch angles between the two compounds illustrate that the columns with short alkoxy chains (six carbons) are more influenced by the presence of other stacks in their vicinity, while those with long side chains are less tilted due to a larger alkoxy (ten carbons) buffer zone. The formation of different packing morphologies in the crystalline phase of a columnar LC has rarely been reported so far, which suggests the possibility of complex stacking structures of similar organic LC systems, utilizing small molecules as potential materials for applications in organic electronics.

\section{Introduction}

Soft matter comprised of spontaneously self-assembled small molecular constituents establishes well-defined mesoscopic supramolecular structures, which determine the macroscopic properties of the material. ${ }^{1}$ Control of the self-organization is achieved by a number of different noncovalent interactions between the single building blocks, including $\pi$-stacking, ${ }^{2}$ hydrogen bonds, ${ }^{3}$ and dipole-dipole interactions, ${ }^{4}$ which can be introduced chemically via specific functional groups. Helical assemblies are one of the most complex systems that have been identified to induce unique properties for a range of different classes of molecular systems such as polymers, ${ }^{5}$ dendrimers, ${ }^{6}$ and disc-shaped molecules. ${ }^{7}$ Chemical modification of the design for single units has a dramatic influence on the supramolecular array. Hereby, nature presents distinctive examples and inspiration for chemists in the form of e.g. DNA. ${ }^{8}$

Thermotropic liquid crystals belong to an important category of soft matter whose molecular order and dynamics are intermediate between the isotropic melt and that of a crystal. ${ }^{9}$ In this class, discotic liquid crystals consisting of planar aromatic cores and peripheral flexible aliphatic substituents create one-dimensional columnar stacks. ${ }^{10}$ For polycyclic aromatic hydrocarbon cores, charge-carrier transport occurs along the columnar structure, which depends on the $\pi$ orbital overlap. ${ }^{11}$ This orbital overlap, in turn, is strongly correlated to the rotational offset angle between adjacent discs, a property that can be controlled via bulky rigid substituents, ${ }^{12}$ core symmetry $^{13}$ or amphiphilic peripheral ${ }^{14}$ interactions.

New types of core architectures for discotic molecules, as alternatives to the rigid aromatic ones, are molecules stiffened by intramolecular non-covalent interactions such as hydrogen bonding. ${ }^{15}$ This strategy allows achieving large disc-shaped systems with efficiently promoted molecular ordering and improved stability in the liquid crystalline phase. Examples of hydrogen- 
bond driven assemblies are complexes of trisalkoxystilbazoles with trimesic acid ${ }^{16}$ or $\mathrm{C}_{3^{-}}$ symmetrical bipyridine. ${ }^{17}$ The latter was found to organize in helically packed columnar structures in the solid state due to rigidification, caused by strong in plane intramolecular hydrogen bonds, and propeller formation after preorganisation by $\pi$-interactions. ${ }^{18} \mathrm{We}$ previously demonstrated a facile way to synthesize discotic hydrazone compounds via the azo-coupling reaction of 1,3,5-trisacetoacetamidobenzene with diazonium salts of aromatic amines. ${ }^{19}$ Hydrazones have potential applications in organic photoconductors, ${ }^{20}$ non-linear optical, ${ }^{21}$ and electroluminescence devices. ${ }^{22}$ Spectroscopic analysis shows that the discotic hydrazones are stabilized through the formation of six intramolecular hydrogen bonds around the central benzene ring, forming a disc-like shape. However, only little is known about their supramolecular organization in the bulk and influence of alkyl substituents on their thermotropic behavior.

In this work, we investigate the thermotropic properties and solid-state organization for a series of hydrazone-based compounds with (achiral) linear alkoxy chains of various lengths (see Figure 1). We use a combination of two-dimensional Wide Angle X-ray Scattering (2DWAXS) and Solid-State Nuclear Magnetic Resonance (SSNMR) techniques. While 2DWAXS provides spatially averaged information about both the overall packing and the molecular arrangement within helical stacks, ${ }^{23}$ SSNMR is sensitive to the local molecular features to determine conformations as well as dynamic processes. ${ }^{24}$ Thus, the combination of these techniques provides information on both short and long-range structural order and dynamical properties for the achiral disc-shaped hydrazone derivatives. In the present case, the molecules have been found to form stacks with tendencies of complex helix formation. The pitch angle of the formed helices depends on the bulkiness and steric demand of the peripheral alkoxy side chains. As demonstrated previously for benzene-1,3,5-tricarboxamides, ${ }^{25}$ the combination of WAXS and SSNMR experiments ${ }^{26}$ with ab initio computations using Gaussian $03^{27}$ and $\mathrm{CPMD}^{28}$ allows us to identify the solid-state packing structures. These studies demonstrate that a length variation of alkoxy-chains can lead to significantly different columnar arrangements, which is reflected in different relative orientations of $\pi$-electron adjacent molecular discs and their overlap. To the best of our knowledge, the structure investigation of coexisting helical packing morphologies in one single columnar liquid crystal is a rare phenomenon and suggests the possibility of packing complexity of similar small, functional molecules as employed in various electronic devices. 


\section{Results and Discussion}

\section{Materials}

We have previously demonstrated a facile way to synthesize discotic hydrazone compounds via the azo-coupling reaction of 1,3,5-trisacetoacetamidobenzene with diazonium salts of aromatic amines (Figure 1, compounds 5-7). ${ }^{19}$ The synthesis route for the derivatives investigated in this work is described in the supporting information. A hydrazone is a tautomer of an azo compound. The coupling reaction of a diazonium salt of an aromatic amine with a nucleophile generally gives a mixture of hydrazone and azo compounds. Tautomerization between two compounds depends on their relative thermodynamic stabilities. The discotic hydrazones are stabilized by the formation of six intramolecular hydrogen bonds around the benzene ring. A hydrazone tautomer exists only at the cost of the resonance stabilization energy of an aromatic ring because an azo group was directly linked to an aromatic ring. For this study, derivatives with three different linear alkoxy side chains (Figure 1, compounds 5-7) were synthesized.

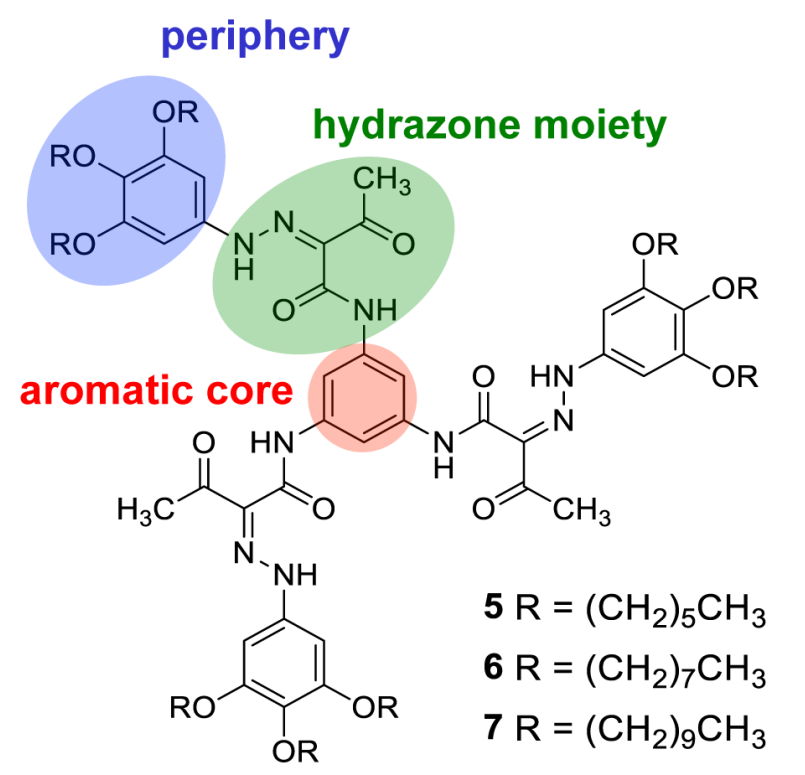

Figure 1. Liquid-crystalline hydrazone derivatives 5-7.

\section{Phase Transitions}

Differential scanning calorimetry (DSC) reveals an expected reduction of the phase transition temperatures with longer alkoxy chains. While the isotropization temperature decreases only slightly for longer side chains, the transition temperature to the columnar ordered $\left(\mathrm{Col}_{\mathrm{h}}\right)$ liquid crystalline (LC) phase drops significantly by changing the chain length from 6 to 8 carbon atoms 
Table 1. Phase Transition Temperatures and Corresponding Enthalpy Values for Compounds 5-7.,

\begin{tabular}{|c|c|}
\hline Compound & $\mathrm{T}\left({ }^{\circ} \mathrm{C}\right)\left[\Delta \mathrm{H}_{\mathrm{t}}, \mathrm{J} / \mathrm{g}\right]$ \\
\hline 5 & H $120[6.8], \mathrm{Col}_{\mathrm{h}} 175[1.1], \mathrm{I}$ \\
\hline 6 & $\mathrm{H} 49[0.8], \mathrm{Col}_{\mathrm{h}} 172$ [2.2], I \\
\hline 7 & H 34 [0.7], $\mathrm{Col}_{\mathrm{h}} 162$ [1.8], I \\
\hline
\end{tabular}

In order to gain a deeper insight into the phase behavior, the optical textures were inspected by polarized optical microscopy (POM). The samples were sandwiched as thin films between two glass slides and cooled down at a rate of $0.1^{\circ} \mathrm{C} / \mathrm{min}$ from the isotropic melt. All three compounds form films without birefringence in POM with cross-polarizers (Figure 2a). Only few birefringent defect structures appear in the image. This optical behavior of the film strongly suggests the spontaneous alignment of the molecules into a homeotropic phase. During the ordering associated with solidification, the discotic columns arrange with their stacking axis perpendicular to the surface. ${ }^{29}$ The structure investigation of the homeotropically aligned thin films by 2DWAXS in transmission confirms the arrangement of the stacks parallel to the surface normal. Characteristically, the patterns show only the hexagonal lattice, which corresponds to intercolumnar ordering (Figure 2b). ${ }^{30}$ 


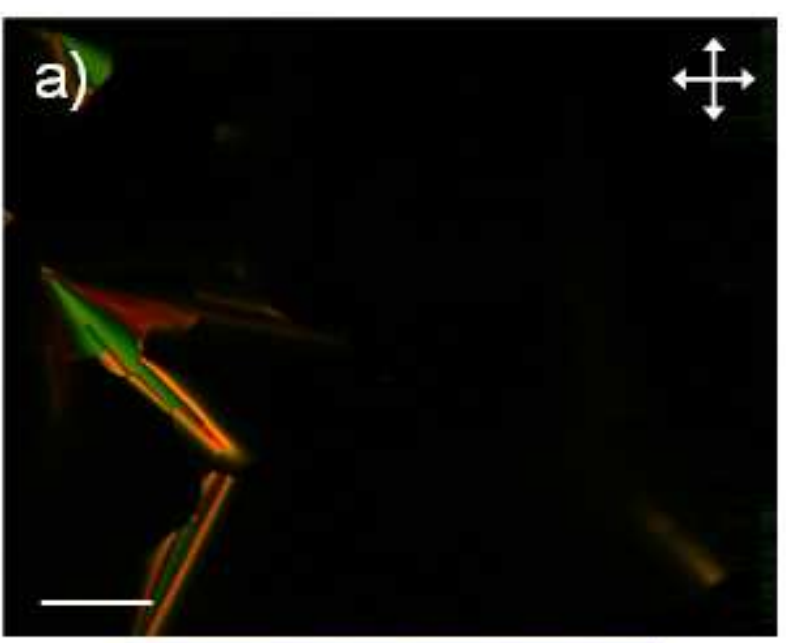

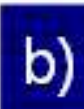 \\ b)}

Figure 2. a) Polarized optical microscopy image of $\mathbf{5}$ obtained in the LC phase between cross-polarizers (scale bar corresponds to $100 \mu \mathrm{m}$ ), b) Transmission 2DWAXS pattern of the corresponding film based on 5.

\section{Long-Range Ordering from 2DWAXS Analysis}

The bulk supramolecular organization was investigated by 2DWAXS of extruded fibers. Already at ambient temperatures, the materials are soft and waxy with a storage modulus of only around $10^{7} \mathrm{~Pa}$ (Figure $\mathrm{S} 1$ for 7 ) that allows the sample extrusion at $25^{\circ} \mathrm{C}$. As mentioned this technique provides valuable information about the molecular arrangement within superstructures possessing long-range order. The fiber samples were mounted vertically, and perpendicular to the incoming beam. The equatorial plane $(h k 0)$ is of particular interest, as it contains small-angle reflections with information about the intercolumnar assemblies (columns) that are aligned in the extrusion direction of the fiber. For discotic fibers, the meridional plane contains wide-angle reflections arising mainly from intracolumnar arrangements, often so-called $\pi$-stacking. Reflections that are located off the meridional and off the equator are the signature of a 3D crystalline phase, and in the case of reduced registry between the columns, these reflections will be the first to fade. 
The scattering patterns can be interpreted in terms of the molecular form factor (of a single discotic molecule) and the structure factor describing the tendencies of 3D packing, including any registry parallel to the columnar direction. As we shall demonstrate, both are important to understand the scattering patterns observed here. For helical structures, the scattering pattern tends to have the intensity distributed on evenly spaced layer lines that are parallel to the equatorial plane. ${ }^{31}$ To simulate the WAXS patterns of various columnar assemblies Cerius ${ }^{2} 32$ and SimDiffraction ${ }^{33}$ have been applied. Throughout in the simulations, the side chains are neglected for simplicity, even though they could contribute to the scattering patterns. ${ }^{34}$

\section{High-Temperature Liquid-Crystalline Phases}

Scattering patterns collected at elevated temperatures are presented in Figure 3, for 5 and 7 (for 6 see Figure S2a), showing that the hexagonal ordering typical for discotic columnar LC phases was found with the columns being highly collinear with the fiber axis. This columnar orientation in the fibers is in accordance with the X-ray data for the homeotropically-aligned film (Figure $2 b$ ), and reports for other columnar discotics. ${ }^{35}$ As expected, the packing parameter increases with the length of the alkoxy side chains, resulting in $a_{\mathrm{hex}}=30.5 \AA$ for $\mathbf{5}, a_{\mathrm{hex}}=33.1 \AA$ for $\mathbf{6}$ and $a_{\text {hex }}=34.4 \AA$ for 7 (Table 2). In the meridional plane a blurred wide-angle reflection appears which we attribute to the intracolumnar organization. The maximum intensity of the meridional scattering feature is found to be directly on the meridional axis, which we interpret as signifying non-tilted hydrazone discs. From the maximum of the meridional scattering, a predominant $\pi$ stacking distance between adjacent discs of $3.5 \AA$ for $\mathbf{5}$ and $\mathbf{6}$ and $3.6 \AA$ for $\mathbf{7}$ was derived. The broad shape of the reflection indicates a rather low degree of intracolumnar order in this phase. We ascribe this lower order in the stacks due to the steric demand of the trialkoxy wedge, which might possess increased molecular dynamics at higher temperatures, resulting in poorer interactions between individual discs. Especially for 7, carrying the longest substituents, the liquid crystalline meridional scattering is blurred out (Figure 3b). In summary, the high temperature phase is assigned to hexagonal columnar $\left(\mathrm{Col}_{\mathrm{h}}\right)$ for all three compounds. 
Table 2. 2D unit cell parameters for the intercolumnar arrangement of 5-7 in different phases as derived from WAXS.

\begin{tabular}{|c|c|c|c|c|}
\hline Compound & Temperature & Phase & Unit cell & Unit cell parameter / $\AA$ \\
\hline \multirow[t]{2}{*}{5} & $25^{\circ} \mathrm{C}$ & $\mathrm{H}$ & Rectangular & $\begin{array}{l}a=29.2 \\
b=18.0\end{array}$ \\
\hline & $130^{\circ} \mathrm{C}$ & $\mathrm{Col}_{\mathrm{h}}$ & Hexagonal & $a=30.5$ \\
\hline \multirow[t]{2}{*}{6} & $25^{\circ} \mathrm{C}$ & $\mathrm{H}$ & Rectangular & $\begin{array}{l}a=33.5 \\
b=64.0\end{array}$ \\
\hline & $130^{\circ} \mathrm{C}$ & $\mathrm{Col}_{\mathrm{h}}$ & Hexagonal & $a=33.1$ \\
\hline \multirow[t]{2}{*}{7} & $25^{\circ} \mathrm{C}$ & $\mathrm{H}$ & Hexagonal & $a=33.1$ \\
\hline & $120^{\circ} \mathrm{C}$ & $\mathrm{Col}_{\mathrm{h}}$ & Hexagonal & $a=34.4$ \\
\hline
\end{tabular}

\section{Low-Temperature Crystalline Phases}

Slow cooling of the samples to $25^{\circ} \mathrm{C}$ leads to a significantly enhanced supramolecular order, as compared to both the initial state directly after fiber extrusion and the high temperature $\mathrm{Col}_{\mathrm{h}}$ phase. A considerable number of spot-like reflections emerge as shown in Figure 4a for $\mathbf{5}$ and Figure 6a for 7 (Figure S2b for 6), which implies a pronounced long-range supramolecular order that can be attributed to the annealing effect of visiting the liquid crystalline $\mathrm{Col}_{\mathrm{h}}$ phase. Based on the crystal structures suggested by 2DWAXS and the SSNMR results showing higher molecular mobilities than normally expected for a crystal (vide infra), the low temperature crystalline phase is assigned for to all three compounds 5, 6 and $7 .^{36}$ The unit cell parameters for the intercolumnar organization for the low temperature phases are summarized in Table 2. Derivatives 5 (Figure 4a) and 6 (Figure S1b) show similar distribution of reflections suggesting closely related molecular organization. After cooling, the hexagonal arrangement of the columns tunes to a rectangular lattice for $\mathbf{5}$ and $\mathbf{6}$ due to a change of the columnar symmetry, while the high temperature unit cell is maintained for 7. The columnar asymmetry for $\mathbf{5}$ and $\mathbf{6}$ is related to the molecular packing, which is described in detail below. It should be noted that the large number of higher order 
reflections indicates a pronounced long-range supramolecular order that can be attributed to the annealing effect in the liquid crystalline $\mathrm{Col}_{\mathrm{h}}$ phase.
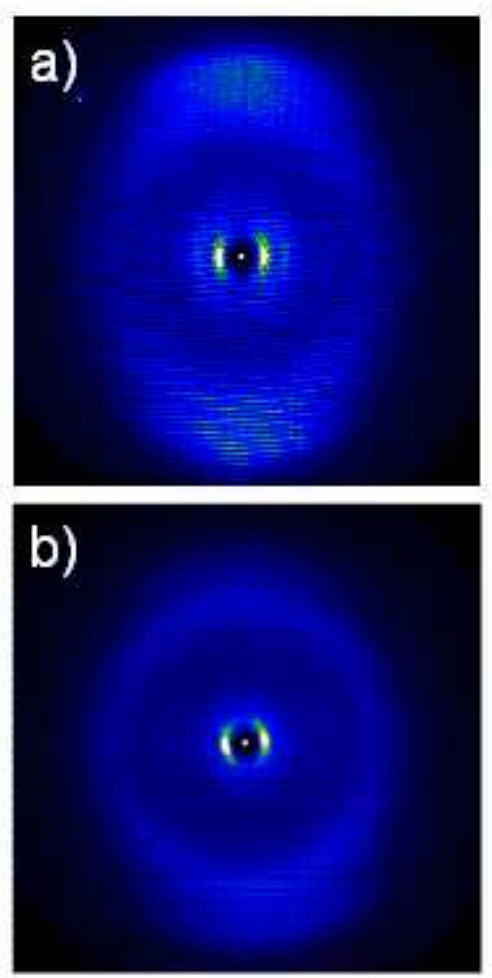

Figure 3. 2DWAXS patterns of a) 5 at $160^{\circ} \mathrm{C}$ and b) 7 at $140{ }^{\circ} \mathrm{C}$ in their LC phases.

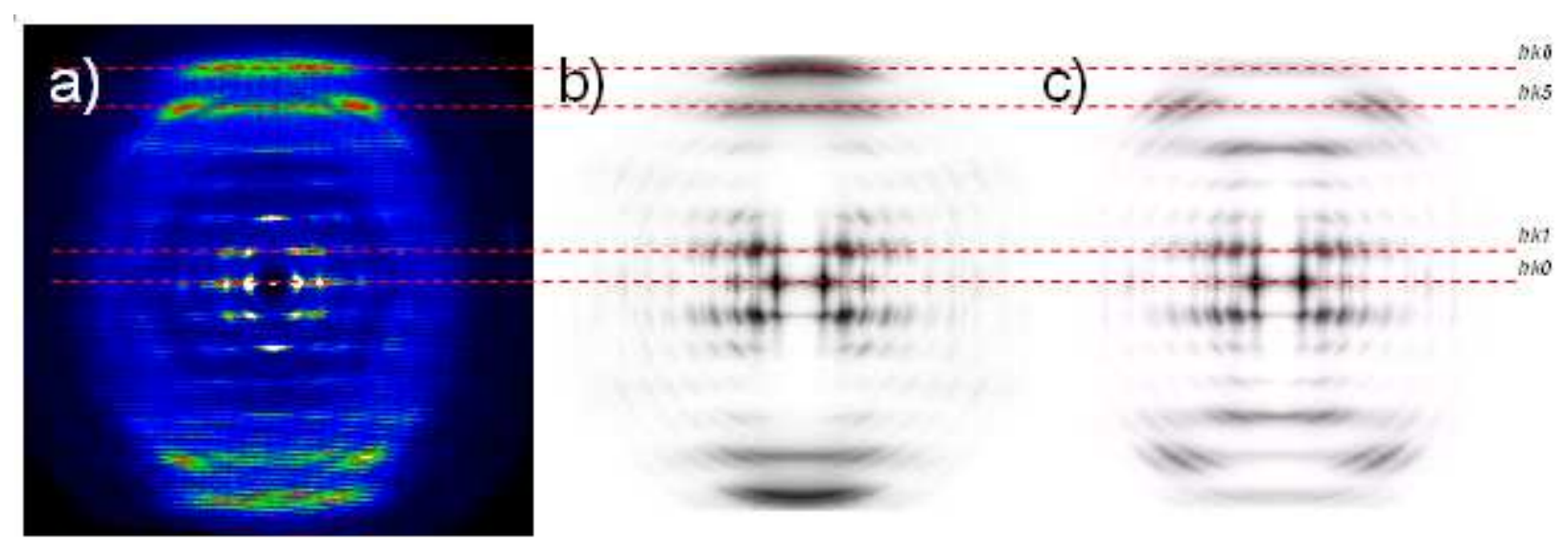

Figure 4. a) $2 \mathrm{DWAXS}$ pattern of 5 at $25^{\circ} \mathrm{C}$, simulations of b) $\mathbf{5 i}$ and c) 5 ii. The scattering lines are assigned by Miller indices and indicate a characteristic helical intracolumnar organization. 


\section{Compound 5 and 6}

Due to the similarities in organization between $\mathbf{5}$ and $\mathbf{6}$, the further analysis is only focused on the first compound. The repetition distance along the columnar axis can be determined from the meridional spacing of the $h k l$ layer lines, corresponding to $20.5 \AA$ for 5 (Figure $4 \mathrm{a}$ ). With the diffraction peaks in the present datasets, there is a certain ambiguity in assigning the number of units to the helical structures. For 5, we thus discuss two alternative molecular packing models which yield fair fits to the X-ray patterns and are also consistent with the later discussed SSNMR results. The first model $\mathbf{5 i}$ is derived from the reflections located on the $h k 6$ line, which are attributed to a small tilt angle of $\sim 12^{\circ}$ of the molecules towards the columnar axis (see illustration in Figure 5). Taking into account the intracolumnar period of $3.5 \AA$, which results from the small tilt angle ( $\pi$-stacking distance of $3.4 \AA$ ), and a helical pitch length of $20.5 \AA, 6$ molecules are necessary for one complete helical winding. Since a full rotation of $120^{\circ}$ is necessary to reach an identical lateral positional order of the $\mathrm{C}_{3}$-symmetric hydrazone molecules within the column, adjacent 5 and 6 molecules are rotated by $20^{\circ}\left(=120^{\circ} / 6\right)$ with respect to each other (Figure 5). The second model 5ii is based on the off-meridional reflections with maximum intensity located on the $h k 5$ line ascribed to a molecular tilting of $\sim 32^{\circ}$ towards the columnar axis (Figure 5 ). ${ }^{37}$ The intracolumnar spacing of $4.1 \AA$ parallel to the columnar axis for such tilted discs is determined from the meridional reflections located also on this layer line. This means that every $5^{\text {th }}$ molecule is in identical positional order within the $20.5 \AA$ long helix pitch. In this model, both $\mathbf{5}$ and $\mathbf{6}$ are rotated by $24^{\circ}\left(=120^{\circ} / 5\right)$ with respect to each other (Figure 5).

The molecular rotation angles of $20^{\circ}$ and $24^{\circ}$ would originate from the steric hindrance of the out-of-plane rotation of the substituents towards the molecular plane. This molecular configuration is in agreement with the previously reported propeller-like structure of bipyridinebased discotics. ${ }^{17 \mathrm{a}}$ However, in the case of $\mathbf{5}$ and $\mathbf{6}$, the propeller arms might be arranged in at least two different conformations, leading to two distinct packing motifs within the columnar stacks. Both discussed models, 5i and 5ii, were simulated in Cerius ${ }^{2}$, which has been recently applied successfully for various complex columnar assemblies, and yield patterns with scattering lines of resembled intensity distributions and number as observed for the experimental data (Figure $4 \mathrm{~b}$ and $4 \mathrm{c}$ ). The fact that several qualitatively different models contain features found in the scattering patterns suggests the proposed coexistence motif of several intracolumnar arrangements. It has to be emphasized that the distinct meridional reflection in the middle-angle 
range on the $h k 2$ scattering line related to a d-spacing of $10.25 \AA$ does not appear in the simulated patterns. Such scattering intensity can be triggered e.g. by the formation of dimers packed in a helical manner as recently reported for liquid crystalline perylene bisimides. ${ }^{32 a}$ That work also demonstrated that the intensity of these reflections is highly sensitive to the configuration of the substituents towards the aromatic core. In our study, various molecular conformations (see examples in Figure S3) concerning the disc planarity and arrangement of the hydrazone side arms, as well as dimer and trimer models with different configurations have been evaluated without fully accounting for the experimental intensity patterns. Despite the immediate appearance of being very similar to $\mathbf{5}$, compound $\mathbf{6}$ deserves a few more comments. In our study, both are found to be consistent with rectangular unit cells. For $\mathbf{5}$, the equatorial diffraction peaks can be indexed using a single-stem rectangular unit cell. A higher-resolution scattering pattern obtained at longer sample-detector distance demonstrates that, contrarily to $\mathbf{5}$ and $\mathbf{7}$, the equatorial reflections for $\mathbf{6}$ are in fact split (Figure S4). The scattering patterns for $\mathbf{6}$ are consistent with a double-stem rectangular lattice, described by a unit cell having $a=33.5 \AA$ and $b=64.0 \AA$, as firmly supported by WAXS simulations. This structure can be considered deformed by about $18 \%$ from the closely related hexagonal structure (Figure S4).



Figure 5. Top and side views of the two packing models for $\mathbf{5}$ with two adjacent discs suggested by 2 DWAXS. For simplicity, the periphery phenyl moieties are omitted. The pitch angles are shown in the top view illustration, while the molecular tilting angles and intracolumnar spacings parallel to the stack axis are given in the side view. 


\section{Compound 7}

The 2DWAXS pattern of $\mathbf{7}$ shows a qualitatively different organization from that observed for $\mathbf{5}$ and 6. For 7, certain gross features of the high-temperature ordering are maintained, in the sense that the intercolumnar packing stays hexagonal and the discs remain non-tilted, while an unambiguous signature of helices develops with an intensity cross. A pronounced meridional reflection points towards no molecular tilting and a $\pi$-stacking distance of $3.4 \AA$ (Figure $6 a$ ). However, as the 2D ${ }^{13} \mathrm{C}\left\{{ }^{1} \mathrm{H}\right\}$ HETCOR spectrum indicates (Figures 10a and 11a), the coexistence of two packing morphologies with tilt angles of $0^{\circ}$ and $15^{\circ}$ can be derived. Cerius 2 simulations confirm that these small differences in intracolumnar packing are not well distinguishable in 2DWAXS of such extruded fibers. The simulated 2DWAXS patterns (Figure $6 \mathrm{~b}$ and c) display qualitatively similar features for both models, where both position and intensity of the reflections are in accordance with the experimental pattern (Figure 6a). Information about the helical organization is obtained again from reflections on layer lines. These suggest a change in the helical packing in comparison to $\mathbf{5}$ and $\mathbf{6}$. From the position of the $h k l$ layer line a helical pitch of $34.0 \AA$ is determined, which includes 10 molecules and thus is larger than for the other two hydrazones. Interestingly, the calculated rotation angle $\left(120^{\circ} / 10\right)$ of $12^{\circ}$ does not correlate well with the SSNMR data and chemical shift calculations (see below). Due to more bulky decyloxy side chains, the angle for 7 is expected to be larger than for 5 and $\mathbf{6}$. Therefore, a full molecular rotation of $360^{\circ}$ within one helical pitch is assumed for 7 , resulting in a molecular twist of $36^{\circ}$ valid for both models $\left(0^{\circ}\right.$ and $\left.15^{\circ}\right)$.

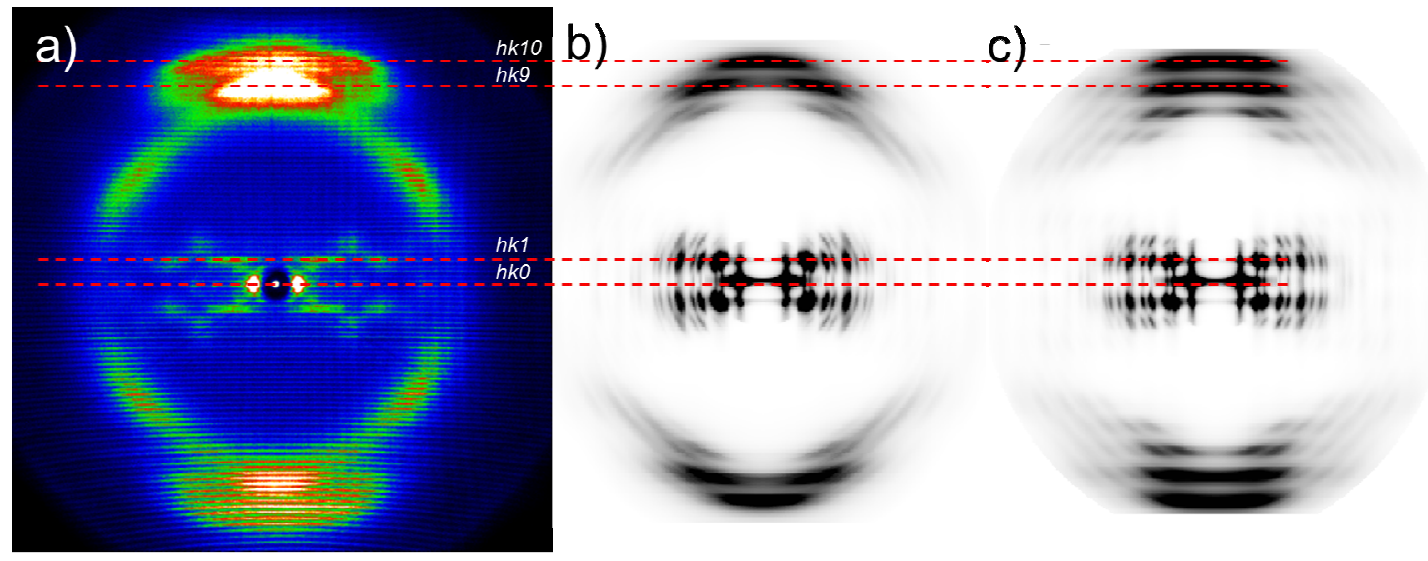

Figure 6. a) 2DWAXS pattern of 7 at $25{ }^{\circ} \mathrm{C}$ after annealing and the corresponding simulated patterns for molecular tilting of b) $0^{\circ}$ and c) $15^{\circ}$. Note the clear tendency of an intensity cross at the origin, being strong evidence for a helical structure. 


\section{Molecular Fingerprints of Stacking Structures from Solid-State NMR}

To complement the 2DWAXS results and gain a deeper insight into the molecular level organization of the discotic hydrazones (Figure 1), we have employed solid-state NMR as a powerful technique to reveal such structural features. ${ }^{26 b, 38}$ This includes notably the sensitivity of ${ }^{1} \mathrm{H}$ NMR towards hydrogen bonding and $\pi-\pi$ stacking. ${ }^{39}$ According to 2DWAXS both compounds 5 and 6 showed similar molecular organizations. We have for this reason chosen to focus only on 5 and 7 in the following. Figure 7a shows the ${ }^{1} \mathrm{H}$ MAS NMR spectra of 5 and 7, where the peak assignments are illustrated using the color scheme given in Figure 7b. A comparison of these spectra shows that 5 has better resolved ${ }^{1} \mathrm{H}$ resonances than $\mathbf{7}$, notably for the hydrazone protons in the range from $10.0 \mathrm{ppm}$ to $14.5 \mathrm{ppm}$. Here, at least three signals for each $-\mathrm{NH}$ - site are observed. In contrast, the ${ }^{1}$ H MAS NMR spectrum of 7 only includes a single, albeit broad signal for each of these positions. The ${ }^{1} \mathrm{H}$ chemical shifts of the resolved signals for $\mathbf{5}$ and $\mathbf{7}$ are listed in Table 3, including their ${ }^{1} \mathrm{H}$ chemical shifts in solution $\left(\mathrm{CDCl}_{3}\right)$. By comparing these data, solid and solution, it is clear that that the dominating hydrazone peaks of $\mathbf{5}$ and $\mathbf{7}$ in the solid phases are shifted to high-field by at more than $1.1 \mathrm{ppm}$ as compared to those in solution. This is a clear indication of a columnar stacking of both compounds. However, the specific stacking structures for 5 and 7 are expected to be different due to the different line shapes observed in the ${ }^{1} \mathrm{H}$ MAS NMR spectra. Moreover, the weak ${ }^{1} \mathrm{H}$ signals at 14.2 and $11.7 \mathrm{ppm}$ from the two different hydrazone protons in $\mathbf{5}$ are very similar to those in solution NMR of 14.7 and $11.6 \mathrm{ppm}$, respectively. Therefore, these signals most likely originate from hydrazone molecules in the nonstacked regions of $\mathbf{5}$, which could include similar dynamics as in solution. For $\mathbf{7}$, the broad line shape of the hydrazone protons does not include a signal at higher frequency, illustrating that no unpacked molecules are present. 
b)

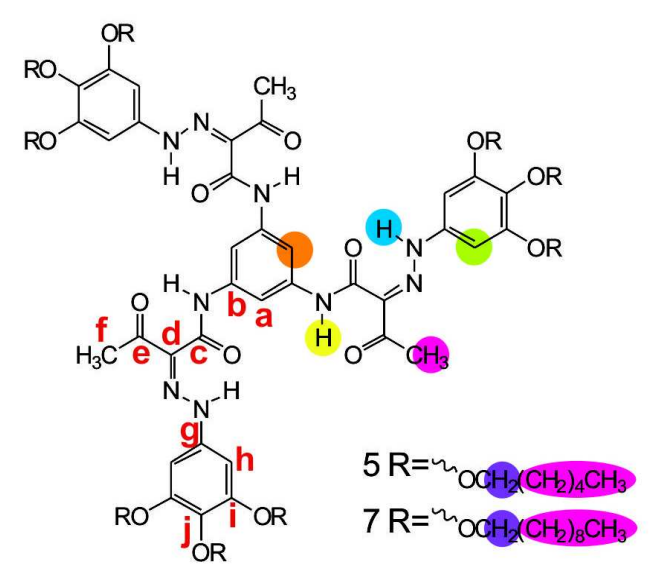

Figure 7. a) Solid-state ${ }^{1} \mathrm{H}$ MAS NMR spectra of 5 (black) and 7 (gray) with assignments given according to the color code shown in b).

Table 3. Solid- and Solution-State ${ }^{1} \mathrm{H}$ Chemical Shifts (in ppm) of the Hydrazone Protons in 5 and 7.

\section{Compound $5 \quad$ Compound 7}

\begin{tabular}{ccccc}
\hline Assignment $^{\mathrm{a}}$ & Solid $^{\mathrm{b}}$ & Solution $^{\mathrm{c}}$ & Solid $^{\mathrm{b}}$ & Solution \\
\hline & 14.2 & & & \\
& 13.6 & 14.7 & 13.4 & 14.8 \\
13.3 & & & \\
\hline 11.7 & & & \\
11.0 & 11.6 & 10.2 & 11.6 \\
& 10.6 & & & \\
\hline
\end{tabular}

${ }^{\mathrm{a}}$ See Figure $7 \mathrm{~b} .{ }^{b}$ Determined from ${ }^{1} \mathrm{H}$ MAS NMR experiments. ${ }^{c}$ Determined from ${ }^{1} \mathrm{H}$ NMR in $\mathrm{CDCl}_{3}$ 
a)
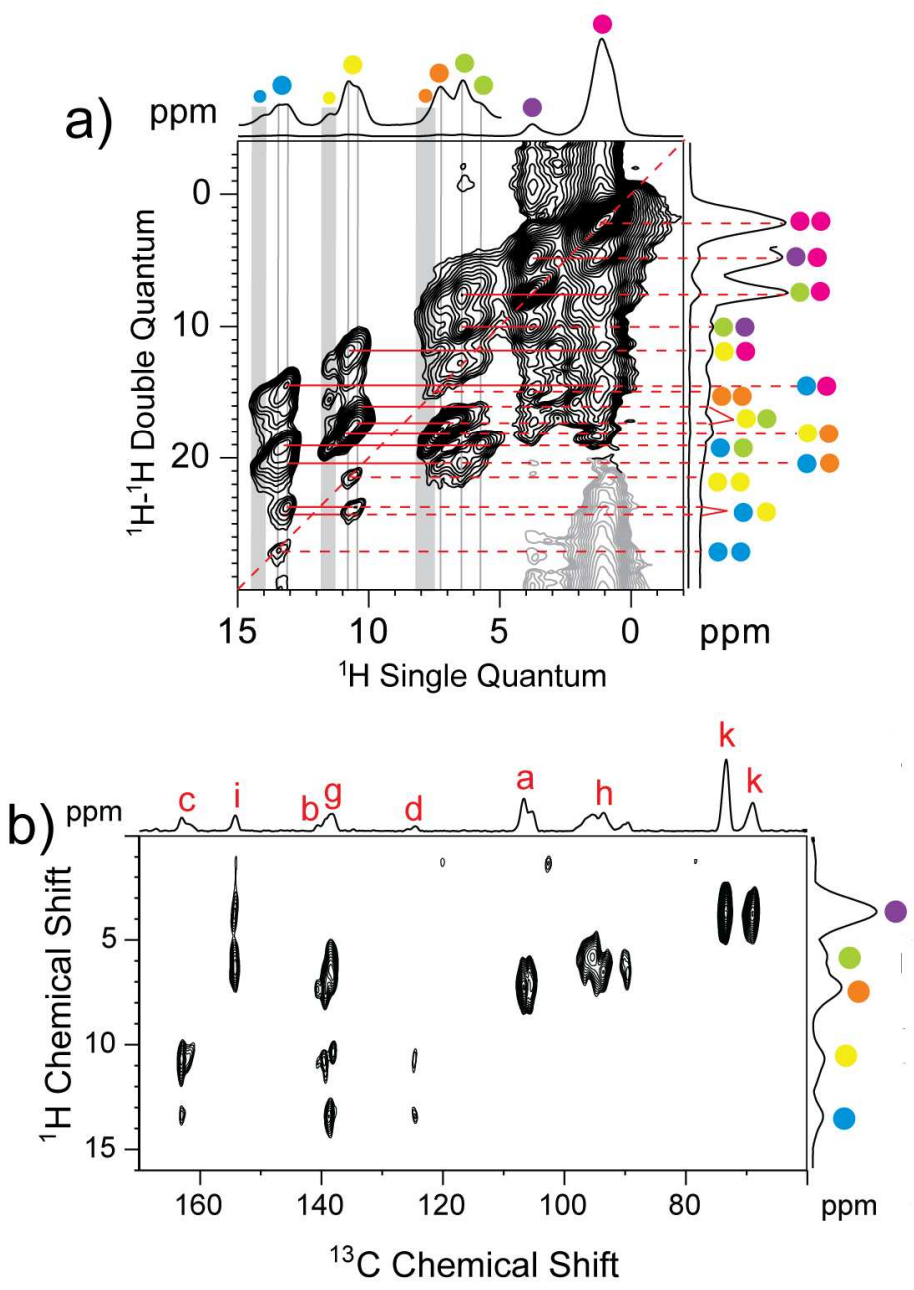

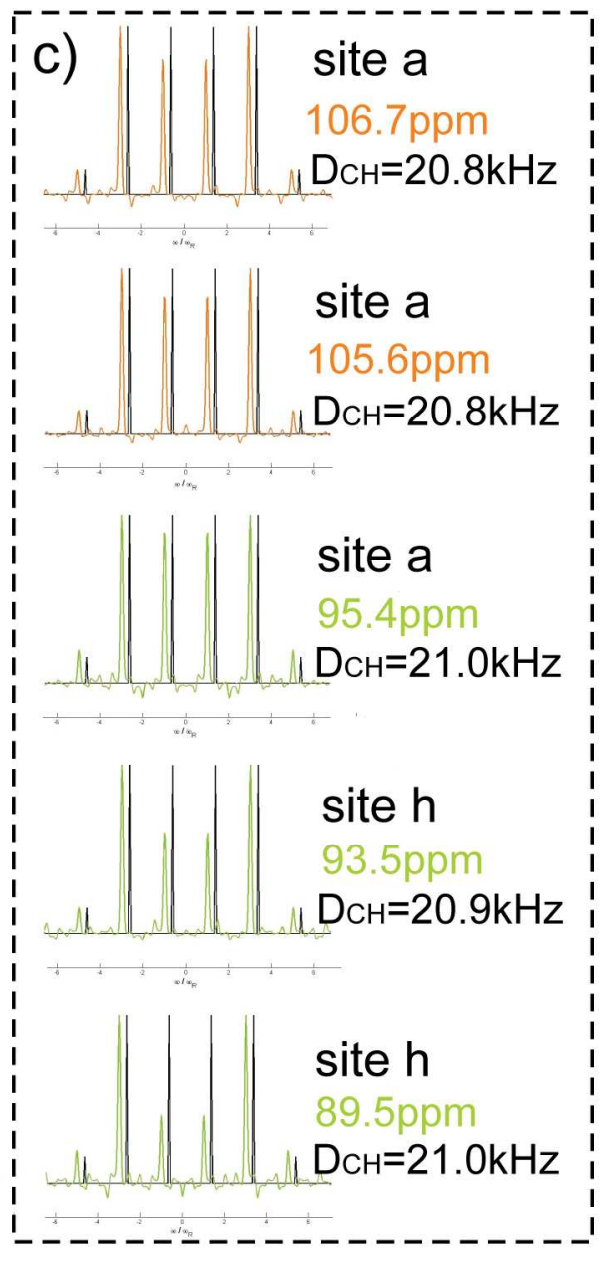

Figure 8. 2D solid-state NMR correlation spectra and molecular dynamic studies of $\mathbf{5}$ in the lowtemperature crystalline phase recorded at $45{ }^{\circ} \mathrm{C}$. a) Rotor-synchronized $2 \mathrm{D}{ }^{1} \mathrm{H}-{ }^{1} \mathrm{H}$ DQ-SQ NMR correlation spectrum and b) $2 \mathrm{D}{ }^{13} \mathrm{C}\left\{{ }^{1} \mathrm{H}\right\}$ REPT-HSQC NMR spectrum. c) Experimental and simulated ${ }^{1} \mathrm{H}-$ ${ }^{13} \mathrm{C}$ dipole-dipole sideband patterns extracted from $2 \mathrm{D}{ }^{13} \mathrm{C}\left\{{ }^{1} \mathrm{H}\right\}$ REPT-HDOR NMR experiments (Figure S5) for the resolved peaks at sites $a$ and $h$.

To further characterize the stacking structure of 5 and 7 we have employed 2D rotorsynchronized ${ }^{1} \mathrm{H}-{ }^{1} \mathrm{H}$ double quantum-single quantum (DQ-SQ) correlation spectroscopy to map out the spatially close protons. Such correlations are very helpful in establishing packing models, since these can be either intramolecular or intermolecular contacts. ${ }^{40}$ Figure 8 a shows the results of this approach for 5, where we have used a short dipole-dipole recoupling period of one rotor period to only detect proton-proton proximities less than $4 \AA .^{41}$ All correlation peaks are assigned using the color-labeling scheme of Figure 7b. Besides the expected intramolecular correlations, the $2 \mathrm{D}$ spectrum also includes remarkable auto-correlation peaks between the two different -NHgroups as well as cross-correlation peaks between them. This demonstrates a spatial proximity of 
less than $4 \AA$ between these chemical moieties that can only come as a result of intermolecular contacts between adjacent molecules in the columnar stacks. In addition, the distance between the two - NH- groups of a single molecule is significantly longer, approximately $4.4 \AA$. Therefore, the cross correlation peaks between the two different $-\mathrm{NH}-$ sites can also be assigned to intermolecular contacts. These findings are in accordance with the 2DWAXS studies at $25{ }^{\circ} \mathrm{C}$, which showed that $\mathbf{5}$ assembles into helical columnar stacks. Based on the stacking parameters derived from 2DWAXS, the detected intermolecular distance between - NH- groups of less than $4 \AA$ is in agreement with the $\pi$-stacking distance of $3.4 \AA$. However, for the weak signals at 11.7 and $14.2 \mathrm{ppm}$, neither auto nor cross correlation signals between them are observed. This observation further supports the assumption that these signals are associated with non-stacked molecules.

Since the transition temperature of 7 from $\mathrm{Col}_{\mathrm{h}}$ to $\mathrm{H}$ phase is at $\sim 34{ }^{\circ} \mathrm{C}$ (see Table 1), all solid-state NMR experiments for this compound were conducted using a cooled gas flow of -16 ${ }^{\circ} \mathrm{C}$ to compensate for the heating effects due to MAS, and thereby maintain a real sample temperature of $\sim 20{ }^{\circ} \mathrm{C}$. Figure 9a shows the resulting ${ }^{1} \mathrm{H}-{ }^{1} \mathrm{H}$ DQ-SQ correlation spectrum of 7. Here, all NH-NH correlations, which were present for 5 are absent, indicating that the intermolecular distances between the two hydrazone $-\mathrm{NH}-$ moieties of each arm for 7 are more than $4 \AA$ away. Since we were not able to distinguish between molecular rotation angles of $12^{\circ}$ and $36^{\circ}$ from 2DWAXS for 7 this result nicely illustrates the power of SSNMR to resolve such molecular packing ambiguities. Thus, the differences in ${ }^{1} \mathrm{H}-{ }^{1} \mathrm{H}$ DQ-SQ spectra between 5 and 7 indicate that the pitch angle between neighboring molecules of $\mathbf{7}$ must be larger than that of $\mathbf{5}$, namely $36^{\circ}$, since both packing organizations for 5 have pitch angles of $20^{\circ}$ and $24^{\circ}$. Moreover, as demonstrated below, the hydrazone moieties in 7 adopt a $40^{\circ}$ out-of-plane conformation, which would be sterically impossible with a molecular rotation angle of $12^{\circ}$. 
a)




Figure 9. 2D solid-state NMR correlation spectra and molecular dynamic studies of 7 recorded in the lowtemperature crystalline phase at $20{ }^{\circ} \mathrm{C}$. a) Rotor-synchronized 2D ${ }^{1} \mathrm{H}-{ }^{1} \mathrm{H}$ DQ-SQ NMR correlation spectrum and b) 2D ${ }^{13} \mathrm{C}\left\{{ }^{1} \mathrm{H}\right\}$ REPT-HSQC NMR spectrum. c) Experimental and simulated ${ }^{1} \mathrm{H}-{ }^{13} \mathrm{C}$ dipoledipole sideband patterns extracted from $2 \mathrm{D}{ }^{13} \mathrm{C}\left\{{ }^{1} \mathrm{H}\right\}$ REPT-HDOR NMR experiments (Figure S5) for the resolved peaks at sites $a$ and $h$.

To reveal details about the local molecular conformations of the hydrazone discs in $\mathbf{5}$ and 7 we have recorded 2D ${ }^{13} \mathrm{C}\left\{{ }^{1} \mathrm{H}\right\}$ REPT-HSQC spectra as shown in Figures $8 \mathrm{~b}$ and $9 \mathrm{~b}$. From these spectra it is apparent that site $a$, corresponding to the core phenyl ring, see Figure $7 \mathrm{~b}$, includes two overlapping signals in the ${ }^{13} \mathrm{C}$ dimension located at 106.7 and $105.6 \mathrm{ppm}$ for $\mathbf{5}$ and 108.0 and $106.4 \mathrm{ppm}$ for 7 . The appearance of two ${ }^{13} \mathrm{C}$ signals indicates that two different chemical environments for the core phenyl protons are coexisting in both compounds. Moreover, both compounds show unequal intensities for these ${ }^{13} \mathrm{C}$ signals along with differences in ${ }^{1} \mathrm{H}$ linewidth of their attached protons. These observations suggest that both position and linewidth of ${ }^{13} \mathrm{C}$ and ${ }^{1} \mathrm{H}$ as revealed by the $2 \mathrm{D}{ }^{13} \mathrm{C}\left\{{ }^{1} \mathrm{H}\right\}$ REPT-HSQC spectra in Figure $8 \mathrm{~b}$ and $9 \mathrm{~b}$ are sensitive to the 
specific packing organization, as confirmed below using Nucleus Independent Chemical Shift calculations (NICS) calculations. Specifically, for the hydrazone compounds studied in this work, we can use the ${ }^{1} \mathrm{H}$ chemical shifts in terms of their positions and associated line widths to characterize the columnar tilt angle and if the hydrazone moieties are out-of-plane with respect to the hydrazone disc (see Figure 1). On this basis, the splitting of the ${ }^{1} \mathrm{H}$ signal observed for $\mathbf{5}$ is expected to originate from two different packing morphologies with quite different tilt angles. For 7, the difference in splitting is lower, indicating that the tilt angles for the two packing morphologies are smaller.

\section{Column Stability via Molecular Dynamics Characterization from Solid-State NMR}

An important aspect to address before combining the static structural results from 2DWAXS and SSNMR with NICS calculations is the stability of the formed columns in $\mathbf{5}$ and $\mathbf{7}$, and if these are influenced by local molecular dynamics of the hydrazone discs. To evaluate this aspect we have recorded site-specific heteronuclear ${ }^{1} \mathrm{H}-{ }^{13} \mathrm{C}$ dipole-dipole couplings (DDCs) using the ${ }^{13} \mathrm{C}\left\{{ }^{1} \mathrm{H}\right\}$ REPT-HDOR and REREDOR techniques. ${ }^{42}$ Both techniques capture the effective heteronuclear ${ }^{1} \mathrm{H}-{ }^{13} \mathrm{C}$ DDCs in the indirect dimension of a $2 \mathrm{D}$ experiment, while maintaining the highresolution conditions offered by MAS in the direct dimension that is needed for ${ }^{13} \mathrm{C}$ resolution. In this manner quantitative information about molecular dynamics is available. ${ }^{43}$ Recent examples utilizing this kind of NMR techniques have been very useful for elucidating complex molecular dynamics in other types of discotic liquid crystals. ${ }^{24}$ The site-specific dynamical order parameter is defined as $S_{C H}=\frac{D_{C H}^{e f f}}{D_{C H}^{\text {rigid }}}$, where $D_{C H}^{\text {eff }}$ is the effective ${ }^{1} \mathrm{H}-{ }^{13} \mathrm{C}$ DDC and $D_{C H}^{\text {rigid }}$ is that of a rigid $\mathrm{CH}$ segment, corresponding to $21.0 \mathrm{kHz}$ in our cases. ${ }^{42}$ Note that the order parameter $\mathrm{S}_{\mathrm{CH}}$ is given in the range from 0 to 1 , corresponding to complete isotropic and rigid conditions, respectively. Figures $8 \mathrm{c}$ and $9 \mathrm{c}$ illustrate the resulting ${ }^{1} \mathrm{H}^{-13} \mathrm{C}$ sidebands patterns for 5 and $\mathbf{7}$, which belong to the well-resolved ${ }^{13} \mathrm{C}$ signals extracted for sites $a$ and $h$ of both compounds. These sites correspond to the core and outer phenyl rings, respectively, see Figure $7 \mathrm{~b}$, for both stacking morphologies discussed above on the basis of solid-state NMR measurements. Figure S5 shows the $2 \mathrm{D}{ }^{13} \mathrm{C}\left\{{ }^{1} \mathrm{H}\right\}$ REPT-HDOR spectra of all aromatic resonances. By fitting these ${ }^{1} \mathrm{H}-{ }^{13} \mathrm{C}$ DDC sideband patterns, given using the color code of Figure $7 \mathrm{~b}$, the effective ${ }^{1} \mathrm{H}-{ }^{13} \mathrm{C}$ DDCs were 
determined and listed next to each sideband pattern in Figures 8c and 9c. The results obtained for the side chains of $\mathbf{5}$ and $\mathbf{7}$ are summarized in Tables S1 and S2. Converting these values into sitespecific order parameters using the relationship given above shows that these, for both types of phenyl sites (core and periphery phenyl moieties) in both stacking morphologies in $\mathbf{5}$ and $\mathbf{7}$, are all very close to 1 . In the $\mathrm{LC}$ phase, these are reduced to $\mathrm{S} \sim 0.4$ for the aromatic core and to $\mathrm{S} \sim 0.1$ for the periphery phenyl rings with very flexible side chains (Figure S8). In the low-temperature crystalline phase, the site-specific order parameters close to 1 indicates a high rigidity of the hydrazone discs and a high stability of the formed stacks on the $\sim$ ms timescale. The attached side chains are on the other hand quite flexible. For 5 this comes as a result of the larger pitch angle between successive molecules allowing the side chains to fill the space. In compound 7, with a lower pitch angle, the dynamical order parameters (Table S2) suggest a more folded state of the side chains, which might be a result of intercolumnar interactions. Meanwhile, the finding that the formed stacks show high stability also indicates that no exchange between two packing morphologies is occurring on the $\sim \mathrm{ms}$ timescale. Another piece of information that can be acquired from the $2 \mathrm{D}{ }^{13} \mathrm{C}\left\{{ }^{1} \mathrm{H}\right\}$ REPT-HDOR experiments is that the non-stacked hydrazone discs observed in compound 5 also behave rather rigid. This illustrates that even though the nonstacked hydrazone molecules do not participate in columnar stacking, they do adopt an amorphous rigid structure rather than a molecular bulk with flexible chemical groups.

\section{Disc Co-Planarity and Columnar Tilt Angles from Ab Initio Calculations}

Based on the 2DWAXS analysis and SSNMR results discussed above we have constructed model stacks for 5 and 7 to determine the molecular packing in terms of pitch and molecular tilt angles within the columnar stacks (see Figure 5) for the two different morphologies observed for each compound. We have adopted the nomenclature $\mathbf{i}$ and $\mathbf{i i}$ for the models with small and large tilt angles, respectively. For 5, the first model (5i) consisted of six helically organized hydrazone molecules with a pitch angle of $20^{\circ}$ and an intracolumnar tilt of $12^{\circ}$, while the second model (5ii) had a larger intracolumnar tilt of $32^{\circ}$ and, hence, a pitch angle of $24^{\circ}$ with only five molecules per complete winding. The second pair of models for 7 had ten molecules per complete winding, a pitch angle of $36^{\circ}$, and an intracolumnar tilt of $0^{\circ}$ and $15^{\circ}$ for the models $7 \mathbf{i}$ and $7 \mathbf{i i}$, respectively. The constructed models were subjected to NICS calculations. Figure S9 shows tilt angles for both compounds in the range from $0^{\circ}$ to $45^{\circ}$. The final tilt angles were derived on the basis of Figure 
S9 as shown in Figures 10 and 11. We estimate the uncertainty for the tilt angles to be in the range of $\pm 5^{\circ}$ for $\mathbf{5}$, while the smaller tilt angles for 7 have larger uncertainties of $\pm 10^{\circ}$. Further details about the NICS calculations are described in the Supporting Information.

a)

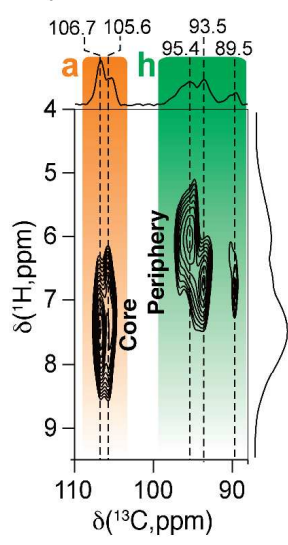

b)

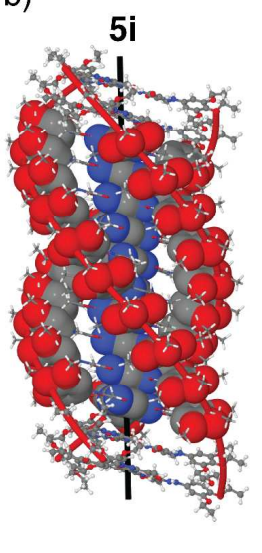

c)



d)

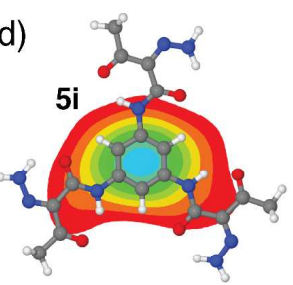

e)

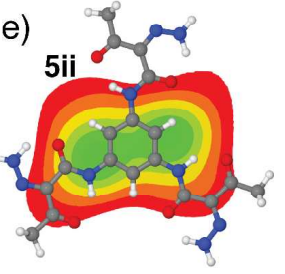

[ppm]

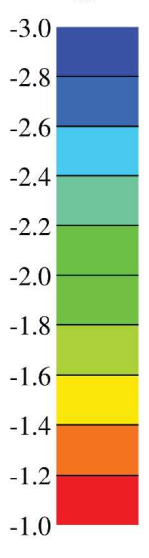

Figure 10. a) Expanded region of the aromatic signals for 5 illustrating the sensitivity of the ${ }^{1} \mathrm{H}$ and ${ }^{13} \mathrm{C}$ resonances at sites $a$ (core) and $h$ (periphery) toward the columnar tilt angle and hydrazone disc coplanarity, respectively. (b and c) Packing models derived for 5i and 5ii with columnar tilt angles of $12^{\circ}$ and $32^{\circ}$ and their corresponding NICS maps shown in d) and e), respectively. The NICS color bar quantifies the NMR chemical shift offset of the core phenyl nuclei (at site $a$ ) induced by the aromatic ring currents of neighboring hydrazone discs. Details relating the disc co-planarity in terms of the arm conformations are given in Figure 12.
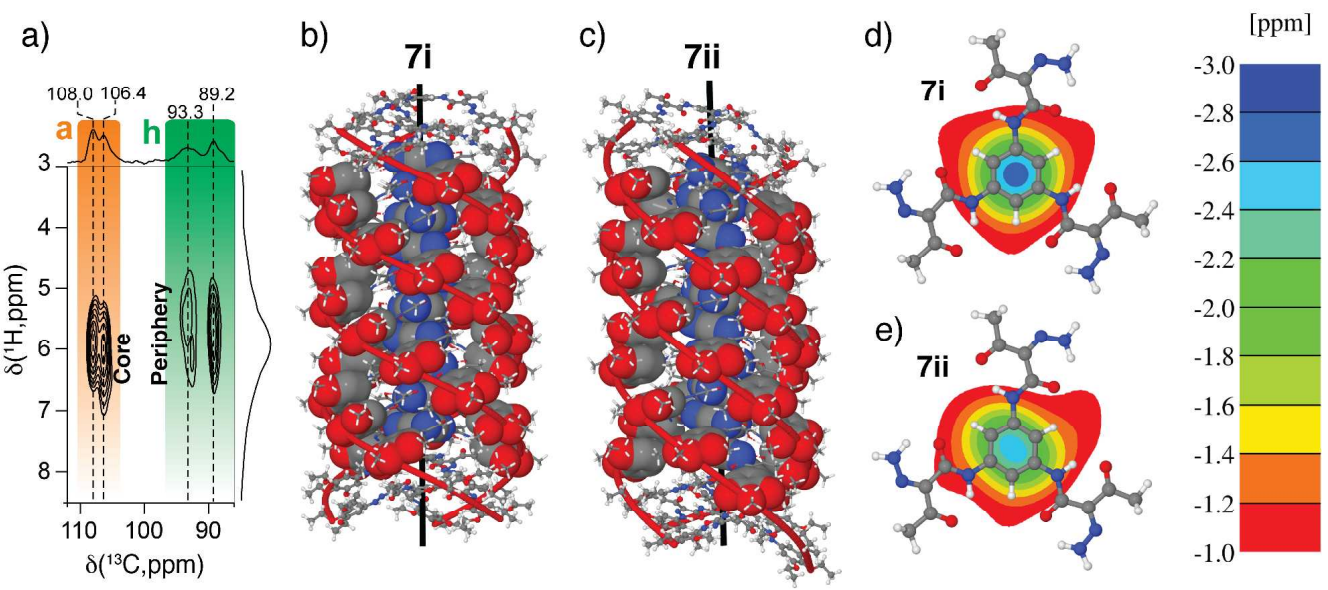

Figure 11. a) Expanded region of the aromatic signals for 7 illustrating the sensitivity of the ${ }^{1} \mathrm{H}$ and ${ }^{13} \mathrm{C}$ resonances of sites $a$ (core) and $h$ (periphery) toward the columnar tilt angle and hydrazone disc coplanarity. (b and c) Packing models derived for 7i and 7ii with columnar tilt angles of $0^{\circ}$ and $15^{\circ}$, and their corresponding NICS maps shown in d) and e), respectively. The NICS color bar quantifies the NMR chemical shift offset of the core phenyl nuclei (site $a$ ) induced by the aromatic ring currents of neighboring hydrazone discs. Details relating the disc co-planarity in terms of the arm conformations are given in Figure 12. 
From an analysis of the resulting NICS maps for 5 (Figures S9, 10d and 10e) and a comparison of these with the expansion of the $2 \mathrm{D}{ }^{13} \mathrm{C}\left\{{ }^{1} \mathrm{H}\right\}$ REPT-HSQC spectrum (Figure 10a), the signal for site $a$, resonating at $106.7 \mathrm{ppm}$ with a narrow line width in the ${ }^{1} \mathrm{H}$ dimension, can be assigned to the stacking morphology of $\mathbf{5 i}$ with a small columnar tilt angle of $12^{\circ}$. In contrast, a larger tilt angle of $32^{\circ}$ results in the breaking of the $\mathrm{C}_{3}$-symmetry for the stacked hydrazone discs and leads to the ${ }^{13} \mathrm{C}$ signal at $105.6 \mathrm{ppm}$ with a broader ${ }^{1} \mathrm{H}$ line width for site $a$, which is associated with the structure 5ii. Compound $\mathbf{7}$ demonstrates the same trends as $\mathbf{5}$. However, due to the longer alkoxy side chains, the columnar stacks in 7 experience less intercolumnar interactions and are for this reason only subject to small tilt angles. We note that control of pitch and tilt angles by varying the chemical nature of the attached side chains have been reported for other discotic systems. ${ }^{44}$ Thus, the signals at $108.0 \mathrm{ppm}$ and $106.4 \mathrm{ppm}$ observed for 7 (Figure 11a) are assigned to the stacking morphologies $7 \mathbf{i}$ and $7 \mathbf{i i}$ with the tilt angles of $0^{\circ}$ and $15^{\circ}$, respectively. We note that our approach of evaluating NICS maps in combination with experimental NMR chemical shifts will be even more useful for revealing tilt and pitch angles in larger discotic systems. This relies on the fact that larger $\pi$-conjugated systems, like those based on hexa-peri-hexa-benzocoronenes (HBCs), show much larger magnetic screening effects as observed here for a rather small discotic system based on a tri-substituted benzene core. ${ }^{45}$

In addition to site $a$, site $h$ (see structure in Figure $7 \mathrm{~b}$ ) also includes two dominating peaks located at 93.5 and 95.4 ppm for 5 (Figure 10a) while these signals appear at 89.2 and 93.3 ppm for 7 (Figure 11a). The resonance at 89.5 ppm observed in 5 is assigned to the non-stacked, amorphous hydrazone discs (see above). From the (planar) chemical structure shown in Figure $7 \mathrm{~b}$, it is apparent that unequal ${ }^{1} \mathrm{H} /{ }^{13} \mathrm{C}$ chemical shifts for the two sites associated with $h$ can only be caused by a difference in their chemical environments. However, if the outer phenyl rings bearing site $h$ are rotated to have a torsional angle of $90^{\circ}$ with respect to the amide plane, the $h$ protons will experience equal environments, resulting in a single ${ }^{1} \mathrm{H} /{ }^{13} \mathrm{C}$ chemical shift for site $h$. Therefore, the experimentally observed ${ }^{13} \mathrm{C}$ chemical shift difference between the two signals of site $h$ can be used to reveal the torsional angle of the outer periphery phenyl groups with respect to the disc plane, i.e., the hydrazone disc co-planarity. 




Figure 12. Torsional angle dependencies for ${ }^{1} \mathrm{H}$ and ${ }^{13} \mathrm{C}$ chemical shifts of the core benzene ring and periphery phenyl rings of a hydrazone disc. The inserts illustrate the two different groups and the definition of their respective torsional angles, whereas the nomenclature cis and trans designate the relative position of the ${ }^{1} \mathrm{H} /{ }^{13} \mathrm{C}$ sites with respect to the $\mathrm{NH}$ group of the periphery phenyl rings.

To characterize the torsional angle dependency of each hydrazone fragment we have performed a Potential Energy Surface (PES) scan for a single hydrazone molecule (see Figure S10), according to the rotational scheme for the benzene core and outer periphery phenyl fragments shown in the inserts of Figure 12. These were conducted at different levels of theory and showed the same trend for the two different methods (MP2 and B97D). Moreover, the PES scans reveal that the amide groups attached to the benzene core can have torsional angles of up to $40^{\circ}$ with respect to the molecular plane caused by thermal motions and packing effects. Obviously, the torsional angle may be even higher in a columnar stack due to the presence of neighboring molecules, leading to more energetically favorable assemblies. It is well known that the chemical shifts of aromatic protons and carbons can serve as reliable sensors towards this kind of conformational freedom. ${ }^{46}$ For this reason we have computed the ${ }^{1} \mathrm{H}$ and ${ }^{13} \mathrm{C}$ chemical shift dependencies as a function of the torsional angles shown in Figure 12. These show that a variation in torsional angle leads to smooth decreasing and increasing curves for the ${ }^{1} \mathrm{H}$ and ${ }^{13} \mathrm{C}$ chemical shifts of both the core benzene and outer phenyl rings. Specifically, it leads to distinct ${ }^{13} \mathrm{C}$ and ${ }^{1} \mathrm{H}$ chemical shifts that enable us to distinguish these two different aromatic moieties (core and periphery) and to evaluate the co-planarity of the hydrazone discs. The latter relies on the fact that ${ }^{13} \mathrm{C}$ chemical shifts for the periphery carbons in trans position with respect to the 
amide groups (see insert of Figure 12) have a stronger dependency towards the torsional angle, which eventually leads to identical ${ }^{13} \mathrm{C}$ chemical shifts at higher torsional angles.

Taking into account the magnetic screening effects as derived from the NICS maps in Figures 10 and 11, which is on the order of $-1.6 \mathrm{ppm}$ for both columnar structures of $\mathbf{5}$ and 7, it is clear that the difference in solid ${ }^{1} \mathrm{H}$ chemical shift between 5 and 7 can only originate from unequal conformations of the hydrazone groups attached to the core phenyl ring. By subtracting the screening effect from 7.4 and 6.5 ppm for 5 and 7 , respectively, one obtains ${ }^{1} \mathrm{H}$ chemical shifts of the free hydrazone discs in their respective conformations of $\sim 9.0$ and $\sim 8.1 \mathrm{ppm}$. These values indicate that phenyl core of $\mathbf{5}$ is planar, whereas compound $\mathbf{7}$ is adopting an out-of-plane conformation for the hydrazone groups with respect to benzene core moiety (see Figure 1), leading to a lower ${ }^{1} \mathrm{H}$ chemical shift. This difference in hydrazone conformation is also reflected in the average ${ }^{13} \mathrm{C}$ positions of the core benzene ring of 106.2 and $107.2 \mathrm{ppm}$ for 5 and 7 , i.e., the higher the ${ }^{13} \mathrm{C}$ chemical shift and the lower the ${ }^{1} \mathrm{H}$ chemical shift, the larger the torsional angle (see Figure 12).

The co-planarity of the peripheral phenyl groups can be evaluated on the basis of the ${ }^{13} \mathrm{C}$ and ${ }^{1} \mathrm{H}$ chemical shift differences observed in Figures 10a and 11a. Here, the splitting differences in ${ }^{13} \mathrm{C}$ and ${ }^{1} \mathrm{H}$ chemical shifts are 1.9 and $0.7 \mathrm{ppm}$ for 5 and 4.1 and $0.2 \mathrm{ppm}$ for 7 , respectively. These chemical shift differences show the opposite trend as for the core benzene ring, since the outer phenyl groups are close to being co-planar with the hydrazone groups in 7 and out-of-plane in 5. Thus, the above calculations of ${ }^{1} \mathrm{H}$ and ${ }^{13} \mathrm{C}$ NMR chemical shifts are very useful for quantifying the disc co-planarity in terms of the torsional angle between the outer periphery phenyl groups and the inner aromatic core. Such calculations can also be useful when characterizing the molecular conformations of larger dendritic structures. ${ }^{47}$

\section{Conclusions}

In this work, three discotic hydrazone compounds with increasing length of linear and achiral alkoxy chains attached to their outer dendritic groups were investigated in terms of their stacking morphologies and thermotropic behavior. The hydrazone molecules are stabilized and rigidified by six intramolecular hydrogen bonds to form stable discotic entities, which self-assemble into columnar structures with three distinct thermodynamic phases. All compounds showed non-tilted 
hexagonal columnar packing $\left(\mathrm{Col}_{\mathrm{h}}\right)$ in their liquid-crystalline phases with only minor differences in their intermolecular $\pi$-stacking distances. Using a multi-technique strategy combining 2DWAXS, SSNMR, and DFT calculations we were able to show that the columnar structures show remarkable differences in their solid phase packing by extending the periphery-attached alkoxy side chains by only two methylene groups. The models found to give the best fits to our experimental data showed that the discotic hydrazone with the shortest alkoxy chains of six carbons included two morphologies with pitch angles of $20^{\circ}$ and $24^{\circ}$ between neighboring molecules and intracolumnar tilt angles of $12^{\circ}$ and $32^{\circ}$, respectively. Similarly, for the longest alkoxy chains with ten carbons, the columnar stacks had a larger pitch angle of $36^{\circ}$ and smaller intracolumnar molecular tilt angles of $0^{\circ}$ and $15^{\circ}$. Both molecules were found by solid-state NMR to have by rigid columns and flexible side chains. Considering that the hydrazone compounds studied here are rather small discotic systems, it can be concluded that the peripheryattached alkoxy chains mainly acts as soft buffer regions between adjacent columns, rendering space for the molecular cores to adopt appropriate tilts. Thus, the specific length of linear alkoxy chains critically determines the molecular helical stacking structure with unexpected complexity. The reason for this complexity most likely has its origin in the energetic balance between flexible side chains and $\pi-\pi$ stacking interactions between the benzene cores, driving the self-assembly. Compared to other discotic systems with significantly larger aromatic cores, the energetic balance is typically in favor of $\pi-\pi$ interactions. For this reason, such systems with larger polycyclic aromatic hydrocarbon cores have not revealed such a packing complexity due to dominant $\pi-\pi$ interactions between the aromatic cores.

To the best of our knowledge the formation of several different packing morphologies in columnar liquid crystals is a rare phenomenon and would be hard to detect using a single technique alone. For this reason, we anticipate that our taken strategy of combining X-ray diffraction and solid-state NMR with DFT calculations of NMR chemical shifts represent a unique possibility to reveal such structural complexities. This kind of information will obviously be crucial for identifying the optimal packing organization and possible stacking defects for small molecules, oligomers, and larger polycyclic aromatic hydrocarbons i.e., when characterizing charge-carrier transport and other physical phenomena that occur on the molecular- and mesolength scales. 
Supporting Information. Material synthesis, characterization and experimental details, and additional WAXS and solid-state NMR experiments. This information is available free of charge via the Internet at http://pubs.acs.org.

Acknowledgment. J. S. and D. D. thank the Max Planck Society for postdoctoral stipends. S.R.P acknowledges the ERC Advanced Grant NANOGRAPH (AdG-2010-267160).

\section{References:}

\footnotetext{
${ }^{1}$ Kato, T.; Mizoshita, N.; Kishimoto, K. Angew. Chem. Int. Ed. 2006, 45, 38-68.

${ }^{2}$ Hoeben, F. J. M.; Jonkheijm, P.; Meijer, E. W.; Schenning, A. P. H. J. Chem. Rev. 2005, 105, 1491-1546.

${ }^{3}$ Gonzalez-Rodriguez, D.; Schenning, A. P. H. J. Chem. Mater. 2011, 23, 310-325.

${ }^{4}$ Datta, A.; Pati, S. K.; Chem. Soc. Rev. 2006, 35, 1305-1323.

${ }^{5}$ Yashima, E.; Maeda K. Macromolecules 2008, 41, 3-12.

${ }^{6}$ Rosen, B. M.; Wilson, C. J.; Wilson, D. A.; Peterca, M.; Imam, M. R.; Percec, V. Chem. Rev. 2009, $109,6275-$ 6540 .

${ }^{7}$ Vera, F.; Serrano, J. L.; Sierra T.; Chem. Soc. Rev. 2009, 38, 781-796.

${ }^{8}$ Davis, J. T.; Spada, G. P Chem. Soc. Rev. 2007, 36, 296-313.

${ }^{9}$ Tschierske, C. Chem. Soc. Rev. 2007, 36, 1930-1970.
}

${ }^{10}$ a) Sergeyev, S.; Pisula, W.; Geerts, Y. H. Chem. Soc. Rev. 2007, 36, 1902-1929; b) Laschat, S.; Baro, A.; Steinke, N.; Giesselmann, F.; Hägele, C.; Scalia, G.; Judele, R.; Kapatsina, E.; Sauer, S.; Schreivogel, A.; Tosoni, M. Angew. Chem. Int. Ed. 2007, 46, 4832-4887.

${ }^{11}$ Pisula, W. Feng, X. L. Müllen, K. Chem. Mater. 2011, 23, 554-567.

12 a) Brunsveld, L.; Zhang, H.; Glasbeek, M.; Vekemans, J. A. J. M.; Meijer, E. W. J. Am. Chem. Soc. 2000, 122 , 6175-6182; b) Pisula, W.; Tomovic, Z.; Watson, M. D.; Müllen, K.; Kussmann, J.; Ochsenfeld, C.; Metzroth, T.; Gauss, J. J. Phys. Chem. B. 2007, 111, 7481-7487.

${ }^{13}$ Feng, X.; Pisula, W.; Müllen, K. J. Am. Chem. Soc. 2007, 129, 14116-14117.

${ }^{14}$ Feng, X. L.; Marcon, V.; Pisula, W.; Hansen, M. R.; Kirkpatrick, J.; Grozema, F.; Andrienko, D.; Kremer, K.; Müllen, K. Nat. Mater. 2009, 8, 421-426.

${ }_{15}$ a) Palmans, A. R. A.; Vekemans, J. A. J. M.; Hikmet, R. A.; Fischer, H.; Meijer, E. W. Adv. Mater. 1998, 10, 873876; b) Percec, V.; Dulcey, A. E.; Balagurusamy, V. S. K.; Miura, Y.; Smidrkal, J.; Peterca, M.; Nummelin, S.; Edlind, U.; Hudson, S. D.; Heiney, P. A.; Duan, H.; Magonov, S. N.; Vinogradov, S. A. Nature 2004, 430, 764-768; c) Percec, V.; Dulcey, A. E.; Peterca, M.; Ilies, M.; Nummelin, S.; Sienkowska, M. J.; Heiney, P. A. PNAS 2006, 103, 2518-2523.

${ }^{16}$ Kleppinger, R.; Lillya, C. P.; Yang C. J. Am. Chem. Soc. 1997, 119, 4097- 4102.

${ }^{17}$ a) van Gorp, J. J.; Vekemans, J. A. J. M.; Meijer, E. W. J. Am. Chem. Soc. 2002, 124, 14759-14769; b) Palmans, A. R. A.; Vekemans, J. A. J. M.; Fischer, H.; Hikmet R. A.; Meijer, E. W. Chem.-Eur. J. 1997, 3, 300-307; c) Palmans, A. R. A.; Vekemans, J. A. J. M.; Havinga, E. E.; Meijer, E. W. Angew. Chem., Int. Ed. 1997, 36, 26482651.

${ }^{18}$ Metzroth, T.; Hoffmann, A.; Martın-Rapun, R.; Smulders, M. M. J.; Pieterse, K.; Palmans, A. R. A.; Vekemans, J. A. J. M.; Meijer, E. W.; Spiess, H. W.; Gauss, J. Chem. Sci. 2011, 2, 69-76.

19 Jeong, M. J.; Park, J. H.; Lee, C.; Chang, J. Y. Org. Lett. 2006, 8, 2221-2224.

${ }^{20}$ Pacansky, J.; Waltman, R. J.; Cox, R. Chem. Mater. 1992, 4, 401-409.

${ }^{21}$ Khan, R. U. A.; Kwon, O.-P.; Tapponnier, A.; Rashid, A. N.; Günter, P. Adv. Funct. Mater. 2006, 16, $180-188$.

${ }^{22}$ Hwang, D.-H.; Park, M.-J.; Lee, J.-H.; Cho, N.-S.; Shim, H.-K.; Lee, C. Synth. Met. 2004, 146, $145-150$.

${ }^{23}$ a) Holst, H. C.; Pakula, T.; Meier, H. Tetrahedron 2004, 60, 6765-6775; b) Shcherbina, M. A.; Zeng, X.; Tadjiev, T.; Ungar, G.; Eichhorn, S. H.; Phillips, K. E. S.; Katz, T. J. Angew. Chem., Int. Ed. 2009, 48, 7837-7840; c) Fontes, 
E.; Heiney, P. A.; Dejeu, W. H. Phys. Rev. Lett. 1988, 61, 1202-1205; d) Barbera, J.; Cavero, E.; Lehmann, M.; Serrano, J.-L.; Sierra, T.; Vazquez, J. T. J. Am. Chem. Soc. 2003, 125, 4527-4533; e) Lehmann, M.; Kestemont, G.; Aspe, R. G.; Buess-Herman, C.; Koch, M. H. J.; Debije, M. G.; Piris, J.; de Haas, M. P.; Warman, J. M.; Watson, M. D.; Lemaur, V.; Cornil, J.; Geerts, Y. H.; Gearba, R.; Ivanov, D. A. Chem. Eur. J. 2005, 11, 3349-3362; f) Peterca, M.; Percec, V.; Imam, M. R. Leowanawat, P.; Morimitsu, K.; Heiney P. A. J. Am. Chem. Soc., 2008, 130, 1484014852; g) Percec, V.; Aqad, E.; Peterca, M.; Imam, M. R. Glodde, M.; Bera, T. K. Miura, Y.; Balagurusamy, V. S. K. Ewbank, P. C.; Würthner, F.; Heiney, P. A. Chem. Eur. J. 2007, 13, 3330-3345.

24 a) Hansen, M. R.; Schnitzler, T.; Pisula, W.; Graf, R.; Müllen, K.; Spiess, H. W. Angew. Chem. Int. Ed. 2009, 48, 4621-4624; b) Tasios, N.; Grigoriadis, C.; Hansen, M. R.; Wonneberger, H.; Li, C.; Spiess, H. W.; Müllen, K.; Floudas, G. J. Am. Chem. Soc. 2010, 132, 7478-7487; c) Hansen, M. R.; Feng, X.; Macho, V.; Müllen, K.; Spiess, H. W.; Floudas, G. Phys. Rev. Lett. 2011, 107, 257801.

${ }^{25}$ Wegner, M.; Dudenko, D.; Sebastiani, D.; Palmans, A. R. A.; de Greef, T. F. A.; Graf, R.; Spiess, H. W. Chem. Sci. 2011, 2, 2040-2049.

${ }^{26}$ a) Brown, S. P. Prog. Nucl. Magn. Reson. Spectrosc. 2007, 50, 199-251, b) Brown S. P.; Spiess, H. W. Chem. Rev. 2001, 101, 4125-4155.

${ }^{27}$ Frisch, M. J. Gaussian 03 Revision D. 02; Gaussian, Inc.: Wallingford, CT, 2004.

${ }^{28}$ Hutter, J.; Parrinello, M.; Marx, D.; Focher, P.; Tuckerman, M.; Andreoni, W.; Curioni, A.; Fois, E.; Roetlisberger, U.; Giannozzi, P.; Deutsch, T.; Alavi, A.; Sebastiani, D.; Laio, A.; VandeVondele, J.; Seitsonen, A.; Billeter, S. Computer code CPMD, version 3.9, 1990-2004, IBM Corp. and MPI-FKF Stuttgart, http://www.cpmd.org

${ }^{29}$ a) Terasawa, N.; Monobe, H.; Kiyohara, K.; Shimizu, Y. Chem. Commun. 2003, 14, 1678- 1679; b) Kroon, J. M.; Koehorst, R. B. M.; van Dijk, M.; Sanders, G. M.; Sudholter, E. J. R. J. Mater. Chem. 1997, 7, 615-624; c) Cammidge A. N.; Gopee, H. J. Mater. Chem. 2001, 11, 2773-2783; d) Bock, H.; Babeau, A.; Seguy, I.; Jolinat P.; Destruel, P. ChemPhysChem 2002, 6, 532-535; e) Wasserfallen, D.; Kastler, M.; Pisula, W.; Hofer, W. A.; Fogel, Y.; Wang Z.; Müllen, K. J. Am. Chem. Soc. 2006, 128, 1334-1339; f) Pisula, W.; Tomovic, Z.; El Hamaoui, B.; Watson, M. D.; Pakula, T.; Müllen, K. Adv. Funct. Mater. 2005, 15, 893-904; g) Pisula, W.; Kastler, M.; El Hamaoui, B.; García-Gutiérrez, M.-C.; Davies, R. J.; Riekel, C.; Müllen, K. ChemPhysChem 2007, 8, 1025-1028; h) Kang, S.-W.; Li, Q.; Chapman, B. D.; Pindak, R.; Cross, J. O.; Li, L.; Nakata, M.; Kumar, S. Chem. Mater. 2007, 19, 5657-5663; i) de Cupere, V.; Tant, J.; Viville, P.; Lazzaroni, R.; Osikowicz, W.; Salaneck, W. R.; Geerts, Y. H. Langmuir 2006, 22, 7798-7806; j) Yoshio, M.; Kagata, T.; Hoshino, K.; Mukai, T.; Ohno, H.; Kato, T. J. Am. Chem. Soc. 2006, 128, 5570-5577; k) Kastler, M.; Pisula, W.; Laquai, F.; Kumar, A.; Davies, R. J.; Baluschev, S.; Garcia-Gutierrez, M.-C.; Wasserfallen, D.; Butt, H.-J.; Riekel, C.; Wegner, G.; Müllen, K. Adv. Mater. 2006, 18, 2255-2259; 1) Gearba, R. I.; Anokhin, D. V.; Bondar, A. I.; Bras, W.; Jahr, M.; Lehmann, M.; Ivanov, D. A. Adv. Mater. 2007, 19, 815-820; m) Hatsusaka, K.; Ohta, K.; Yamamoto, I.; Shirai, H. J. Mater. Chem. 2001, 11, 423-433; n) Grelet, E.; Bock, H. Europhys. Lett. 2006, 73, 712-718.

${ }^{30}$ a) Osawa, T.; Kajitani, T.; Hashizume, D.; Ohsumi, H.; Sasaki, S.; Takata, M.; Koizumi, Y.; Saeki, A.; Seki, S.; Fukushima, T.; Aida, T. Angew. Chem. Int. Ed. 2012, 51, 7990-7993; b) Thiebaut, O.; Bock, H.; Grelet, E. J. Am. Chem. Soc. 2010, 132, 6886-6887.

${ }^{31}$ a) Percec, V.; Glodde, M.; Bera, T. K.; Shiyanovskaya, I.; Singer, K. D.; Balagarusamy, V. S. K.; Heiney, P. A.; Schnell, I.; Rapp, A.; Spiess, H.-W.; Hudson, S. D.; Duan H. Nature 2002, 419, 384-387; b) Percec, V.; Imam, M. R.; Peterca, M.; Wilson, D. A.; Graf, R.; Spiess, H. W.; Balagurusamy, V. S. K.; Heiney, P. A. J. Am. Chem. Soc. 2009, 131, 7662-7677; c) Percec, V.; Glodde, M.; Peterca, M.; Rapp, A.; Schnell, I.; Spiess, H. W.; Bera, T. K.; Miura, Y.; Balagurusamy, V. S. K.; Aqad, E.; Heiney P. A. Chem-Eur. J. 2006, 12, 6298-6314; d) Percec, V.; Imam, M. R.; Peterca, M.; Wilson, D. A.; Heiney, P. A. J. Am. Chem. Soc. 2009, 131, 1294-1304; e) Livolant, F.; Levelut, A. M.; Doucet, J.; Benoit, J. P. Nature 1989, 339, 724-726; f) Lehmann, M.; Jahr, M.; Donnio, B.; Graf, R.; Gemming, S.; Popov, I. Chem. Eur. J. 2008, 14, 3562-3576; g) Pisula, W.; Kastler, M.; Wasserfallen, D.; Robertson, J. W. F.; Nolde, F.; Kohl, C.; Müllen, K. Angew. Chem. Int. Ed. 2006, 45, 819-823; h) Feng, X.; Pisula, W.; Takase, M.; Dou, X.; Enkelmann, V.; Wagner, M.; Ding, N.; Müllen, K. Chem. Mater. 2008, 20, 2872-2874.

32 a) V.; Percec, M.; Peterca, T.; Tadjiev, X.; Zeng, G.; Ungar, P.; Leowanawat, E.; Aqad, M. R.; Imam, B. M.; Rosen, U.; Akbey, R.; Graf, S.; Sekharan, D.; Sebastiani, H. W.; Spiess, P. A.; Heiney, S. D.; Hudson, J. Am. Chem. Soc. 2011, 133, 12197-12219; b) Zöphel, L.; Mali, K. S.; Reddy, P. S.; Wagner, M.; De Feyter, S.; Pisula, W.; Müllen, K. Chem-Eur. J. 2012, 18, 3264-3276, c) Percec, V.; Hudson, S. D.; Peterca, M.; Leowanawat, P.; Aqad, E.; 
Graf, R.; Spiess, H. W.; Zeng, X.; Ungar, G.; Heiney, P. A. J. Am. Chem. Soc. 2011, 133, 18479-18494; d) Peterca, M.; Imam, M. R.; Ahn, C.-H.; Balagurusamy, V. S. K.; Wilson, D. A.; Rosen, B. M.; Percec, V. J. Am. Chem. Soc. 2011, 133, 2311-2328.

${ }_{33}$ Breiby, D.W.; Bunk, O.; Andreasen, J. W.; Lemke, H. T.; Nielsen, M. M. J. Appl. Crystallogr. 2008, 41, $262-271$.

${ }^{34}$ Breiby, D. W.; Bunk, O.; Pisula, W.; Sølling, T. I.; Tracz, A.; Pakula, T.; Müllen, K.; Nielsen, M. M. J. Am. Chem. Soc. 2005, 127, 11288-11293.

${ }^{35}$ Pisula, W.; Feng, X.; Müllen, K. Adv. Mater. 2010, 22, 3634-3649.

${ }^{36}$ Glusen, B.; Heitz, W.; Kettner, A.; Wendorff, J. H. Liqu. Cryst. 1996, 20, 627-633.

${ }^{37}$ Shen, H.; Jeong, K.-U.; Xiong, H.; Graham, M. J.; Leng, S.; Zheng, J. X.; Huang, H.; Guo, M.; Harris, F. W.; Cheng, S. Z. D. Soft Matter, 2006, 2, 232-242

38 Brown, S. P. Solid State Nucl. Magn. Reson. 2012, 41, 1-27.

${ }^{39}$ Bohle, A.; Brunklaus, G.; Hansen, M. R.; Schleuss, T. W.; Kilbinger, A. F. M.; Seltmann, J.; Spiess, H. W. Macromolecules 2010, 43, 4978-4985.

${ }^{40}$ Dudenko, D.; Kiersnowski, A.; Shu, J.; Pisula, W.; Sebastiani, D.; Spiess, H. W.; Hansen, M. R. Angew. Chem. Int. Ed. 2012, 51, 11068-11072.

${ }^{41}$ Schnell, I.; Spiess, H. W. J. Magn. Reson. 2001, 151, 153-227.

${ }^{42}$ Saalwächter, K.; Schnell, I. Solid State Nucl. Magn. Reson. 2002, 22, 154-187.

${ }^{43}$ Hansen, M. R.; Graf, R.; Spiess, H. W. Acc. Chem. Res. 2013. DOI: $10.1021 /$ ar300338b.

${ }^{44}$ May, F.; Marcon, V.; Hansen, M. R.; Grozema, F.; Andrienko, D. J. Mater. Chem. 2011, 21, 9538-9545.

45 a) Ochsenfeld, C.; Brown, S. P.; Schnell, I.; Gauss, J.; Spiess, H. W. J. Am. Chem. Soc. 2001, 123, 2597-2606; b) Sebastiani, D.; Kudin, K. N. ACS Nano 2008, 2, 661-668.

${ }^{46}$ a) Hirschinger, J.; Kranig, W.; Spiess, H. W. Colloid Polym Sci 1991, 269, 993-1002; b) Fritzsche, M.; Bohle, A.; Dudenko, D.; Baumeister, U.; Sebastiani, D.; Richardt, G.; Spiess, H. W.; Hansen, M. R.; Höger, S. Angew. Chem. Int. Ed. 2011, 50, 3030-3033.

${ }^{47}$ a) Rapp, A.; Schnell, I.; Sebastiani, D.; Brown, S. P.; Percec, V.; Spiess, H. W. J. Am. Chem. Soc. 2003, 125, 13284-13297.

\section{Table of content graphic}

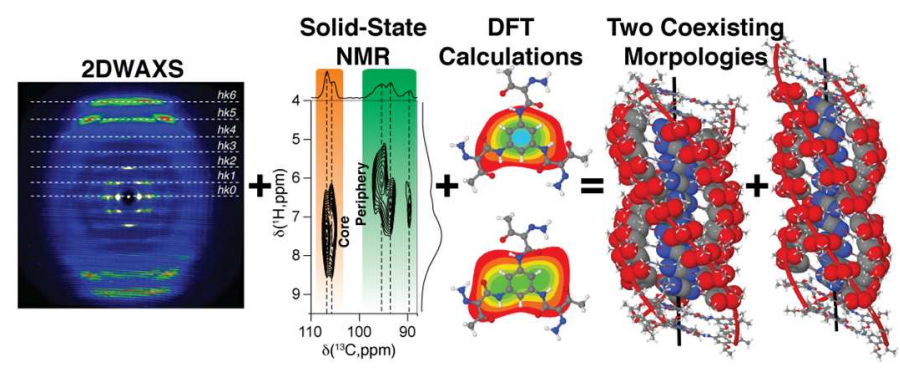

